\title{
MÍDIA, ESCOLA E LEITURA CRÍTICA DO MUNDO
}

\author{
Graça Caldas \\ A leitura do mundo precede \\ a leitura da palavra. \\ (Paulo Freire) \\ Os cidadãos civilizados não são produto do acaso, \\ mas de um processo educativo.
}

(Karl Popper)

RESUMO: O texto faz uma reflexão sobre o uso da imprensa na sala de aula e sua relação com o processo de aprendizagem. Questiona a excessiva inserção de fragmentos do discurso jornalístico nos livros didáticos em detrimento de outros gêneros. Discute a qualidade da narrativa jornalística e os riscos que ela encerra se não houver uma leitura crítica da mídia. Defende a necessidade de trabalho integrado entre educadores e jornalistas para a real compreensão do processo de produção da imprensa, construção da linguagem e da linha editorial dos veículos de comunicação.

Palavras-chave: Mídia. Linguagem. Educação. Leitura crítica.

\section{MEDIA, SCHOOL AND CRITICAL READING OF THE WORLD}

ABSTRACT: This paper focuses on the classroom use of newspaper and magazine texts and its connection with the learning process. It criticizes the excessive usage of fragments of journalistic discourse in school textbooks, to the detriment of other text forms. The quality of journalistic narration is questioned and the risks incumbent on an

* Doutora em Ciências da Comunicação pela Universidade de São Paulo (USP); professora e pesquisadora do Programa de Pós-Graduação em Comunicação Social da Universidade Metodista de São Paulo (Umesp); coordenadora científica da Pós-Graduação das Faculdades Metropolitanas de Campinas (METROCAMP); professora e pesquisadora associada do curso de Jornalismo Científico do LABJOR/UniCAMP.E-mail: gcaldas@unicamp.br 
Mídia, escola e leitura crítica do mundo

acritical reading of the media. It advocates the necessity of cooperation between educators and journalists to foster an effective understanding of the news production process, to improve language construction, and to generate awareness of the medias editorial lines and policies.

Key words: Media. Language. Education. Critical reading.

\section{Introdução}

$\mathrm{O}$

s percursos metodológicos entre as áreas de comunicação e educação vêm sendo trilhados há muito tempo, de forma paralela, sem que os especialistas desses campos do conhecimento consigam chegar a um denominador comum para a interface necessária no uso adequado da mídia na escola. Nas sociedades modernas, em que os meios de comunicação interferem diretamente na formação/deformação das pessoas, sejam elas crianças, jovens ou adultos, não há mais como negar a importância de pesquisas integradas entre esses dois campos de estudo para resultados mais eficazes nos procedimentos pedagógicos das escolas.

Como se dá o processo de compreensão de conteúdos programáticos nas salas de aula em face da utilização cada vez mais freqüente dos recursos midiáticos? Como lidar com o conhecimento formal, necessário e indispensável à formação dos alunos, quando são permeados/ atravessados pela velocidade do mundo da notícia, pela transformação do real em virtual e pela dificuldade crescente de compreensão na leitura dos textos e, conseqüentemente, na leitura do mundo? Em que medida a crescente utilização da mídia na escola pode melhorar ou servir como estímulo ao processo de cognição dos alunos? A sacralização da mídia como ferramenta didática contribui, de fato, para uma leitura crítica do mundo real?

\section{Ler e compreender}

Recentes pesquisas nacionais e internacionais, como do Sistema Nacional de Avaliação da Educação Básica (SAEB), do Exame Nacional do Ensino Médio (ENEM) e do Programa Internacional de Avaliação dos Estudantes (PISA), revelam o baixíssimo nível de compreensão, interpretação e reflexão dos alunos do Ensino Fundamental e Médio. Nos exames de acesso à universidade a situação não é muito diferente. 
A incapacidade de leitura para além dos códigos lingüísticos dos alunos, sejam eles de escolas públicas ou privadas, tem sido objeto de reflexão dos educadores brasileiros para identificar as causas e encontrar caminhos para alteração desta realidade. Não são poucos os especialistas que apontam as fragilidades do sistema educacional do país, tais como: superficialidade, excesso de conteúdo e pouco cuidado com a linguagem.

Em que medida, porém, a dificuldade de interpretação dos fatos pode ser creditada aos problemas comuns na formação dos professores, à débil cultura dos alunos ou às não menos frágeis estruturas narrativas da mídia? A incorporação de fragmentos de textos da imprensa nos livros didáticos não favorece a leitura crítica do mundo, porque são eles próprios, além de recortes, versões da realidade. Não são poucas as vezes em que os textos jornalísticos distorcem as suas relações entre presente, passado e futuro, razão pela qual dificultam a percepção crítica do mundo por não estabelecerem as necessárias conexões entre os fatos presentes com suas causas e conseqüências.

O baixo índice de leitura no país, associado à inexistência de bibliotecas públicas em "21,3\% dos 5.559 municípios brasileiros" (Bertoletti, 2004, p. 86), atesta a falta de investimento das autoridades para tornar disponível o acesso ao livro no país. Projetos recentes do governo federal, como o "Fome do Livro", que pretendem modificar esta realidade, ampliando o acesso e a distribuição do livro no país, ainda têm um longo percurso pela frente, razão pela qual o papel da escola é ainda fundamental na formação de leitores.

A recente pesquisa Retrato da Leitura do Brasil, realizada por Câmara Brasileira do Livro (CBL), Sindicato Nacional dos Editores de Livros (SNel), Associação Brasileira de Editores de Livros (Abrelivros) e Associação Brasileira de Celulose e Papel (BRACELPA), traz um perfil preocupante do leitor brasileiro. Com um universo de 5.503 entrevistas de 40 cidades brasileiras, representando uma população estimada em 86 milhões de pessoas (correspondente a cerca de $40 \%$ da população do Brasil), os resultados revelam que $61 \%$ dos brasileiros adultos alfabetizados têm pouco ou nenhum contato com os livros. Além disso, de acordo com os dados divulgados pela revista Carta Capital (9/ 11/2005, p. 22), na Região Sudeste "apenas 7\% dos estudantes alcançaram níveis 'adequados' de leitura”. 
Mídia, escola e leitura crítica do mundo

Como superar este impasse? Nas sociedades modernas, em que o acesso à informação virou business, mercadoria preciosa e moeda de troca do capitalismo, o conhecimento, por sua vez, tornou-se cada vez mais exíguo e, por isso mesmo, fonte permanente de poder. De que adianta, portanto, a leitura da palavra, se a leitura do mundo não está sendo feita para a necessária articulação entre fatos, contexto e visão prospectiva do mundo?

Como formar o cidadão frente à influência avassaladora da mídia no quadro de uma cultura pós-moderna fragmentada e fragmentadora? Qual o papel da escola neste processo? Quem mais uma vez educará os educadores? E quem forma os comunicadores? Qual seria, então, o caminho para a construção da cidadania pós-moderna e para garantir, assim, a sua emancipação? (Caldas, 2005, p. 94)

\section{Papel do jornal na escola}

Qual seria, então, o papel da escola na formação do leitor? O hábito da leitura pode ser melhorado com a inserção da mídia na escola? Leitura crítica da mídia se aprende na sala de aula? O que é necessário para o exercício cidadão da leitura do mundo? Simultaneamente à perda sucessiva de leitores, os jornais descobriram um importante nicho no mercado editorial: a escola.

Os grupos de mídia, principalmente os impressos: jornais e revistas, começaram a distribuir os encalhes de seus exemplares e a produzir versōes direcionadas à sala de aula. Este movimento pela inserção do jornal e da revista na sala de aula, como prática pedagógica, ganhou força no início da década de 1990 e ainda hoje continua conquistando novos adeptos, como é o caso da revista Carta Capital, que lançou em outubro de 2005 sua versão pedagógica. Ao anunciar sua inserção no mundo da escola, essa versão da revista passa a disputar um importante espaço atuando diretamente no processo educativo na formação de professores e alunos sobre os acontecimentos da realidade.

A formação de cidadãos, atributo da escola, passa hoje obrigatoriamente pela habilitação do cidadão para ler os meios de comunicação, sabendo desvelar os implícitos que a edição esconde; sendo capaz de diferenciar, entre os valores dos produtores dos meios, aqueles que estão mais de acordo com a identidade de sua nação; reconhecendo os posicionamentos ideoló- 
gicos de manutenção do status quo ou de construção de uma variável histórica mais justa e igualitária. E, para isso, a escola não pode esquecer-se do ecossistema comunicativo no qual vivem os alunos. Ou seja, ou a escola colabora para democratizar o acesso permanente a esse ecossistema comunicativo ou continuará a operar no sentido da exclusão, tornando maiores os abismos existentes. (Baccega, 2003, p. 81)

Segundo dados do diagnóstico sobre os Programas de Jornal na Educação Brasileira, realizado pela Associação Nacional dos Jornais (ANJ), com 129 empresas jornalísticas associadas, no período de maio a agosto de 2004, existem atualmente 48 programas ativos nas escolas, dos quais a grande maioria (18) está concentrada na Região Sudeste. O primeiro projeto é do jornal $O$ Globo e surgiu em 1982. Mas foi na década de 1990 que se observou um crescimento contínuo de projetos similares, em vários pontos do país.

Os objetivos das empresas de comunicação, de acordo com os resultados da pesquisa são principalmente: incentivar a leitura de jornais; incentivar outras leituras; ensinar o aluno como é o jornal; promover o debate sobre o papel da imprensa; capacitar o aluno a ler criticamente o jornal; promover o respeito à opinião divergente; aproximar a escola das questôes do cotidiano; facilitar uma aproximação entre os professores; tornar o currículo mais dinâmico; ajudar o aluno a se expressar melhor e com maior confiança em si; contribuir para que o aluno escreva melhor; facilitar a criação do jornal escolar; contribuir para o aprendizado informal da língua; contribuir para que o aluno conheça melhor o mundo em que vive; contribuir para o exercício da cidadania e colaborar para a construção de um conhecimento mais amplo e multidisciplinar do aluno.

Embora os objetivos educativos anunciados pelas empresas na pesquisa da ANJ sejam legítimos, na prática, a avaliação dos próprios responsáveis pelos respectivos programas indica que os resultados mais favoráveis $(61 \%)$ estão concentrados na formação de novos leitores, no conhecimento do aluno sobre o processo de produção dos jornais (74\%), na aproximação da escola das questôes do cotidiano $(76 \%)$ e na contribuição para que o aluno conheça melhor o mundo em que vive $(60 \%)$, além de contribuir, também, para o exercício da cidadania (57\%). Em contrapartida, a promoção do incentivo à leitura é baixa (24\%), assim como favorece pouco a criação do jornal escolar (28\%). 
Mídia, escola e leitura crítica do mundo

Sem desconsiderar a importância dos projetos de mídia na escola, que vêm sendo desenvolvidos pelas empresas de comunicação, é fundamental refletir sobre a qualidade do uso da mídia na sala de aula, seja na utilização plena de seus veículos originais ou em suas versōes para a escola. Como formar professores na leitura crítica da mídia para que os conteúdos noticiados pela imprensa sejam adequadamente interpretados e devidamente relativizados na construção do conhecimento? Discutir as tensões, os conflitos, os problemas éticos que envolvem a construção da notícia na sua relação com o mercado não é tarefa menos importante para dar a real dimensão do processo de produção da mídia e das contradições inerentes a este.

Aprender sobre o mundo editado pela mídia, a ler além das aparências, a compreender a polifonia presente nos enunciados da narrativa jornalística, não é tarefa fácil, mas desejável para uma leitura crítica da mídia. Discutir a responsabilidade social da imprensa, do jornalista, compreender as intrincadas relações de poder que estão por trás da composição dos veículos; capacitar professores e alunos para entender os sentidos, o significado implícito no discurso da imprensa não são tarefas fáceis. Exigem muito mais que a competência do fazer jornalístico e o entendimento claro de que a linguagem utilizada pela mídia encerra múltiplas interpretaçōes, razão pela qual a leitura da mídia na escola não deve restringir-se à leitura de um veículo, mas à pluralidade dos meios. É necessário reconhecer, portanto, que a linguagem é, por natureza, ideológica.

Toda linguagem é ideológica porque, ao refletir a realidade, ela necessariamente a refrata. Há sempre, queira-se ou não, uma transfiguração, uma obliqüidade da linguagem em relação àquilo a que ela se refere. Por usa própria natureza, de mediadora entre nós e o mundo, a linguagem apresenta sempre, inelutavelmente, um descompasso em relação à realidade. Ela não é, nem pode ser a realidade. A essa diferença substantiva entre a linguagem e o real acrescentam-se as diferenças adjetivas, quer dizer, as variações próprias às posições históricas e sociais dos agentes que a produzem e consomem. (Santaella, 1996, p. 330-331)

Como então formar professores para que o uso da mídia na sala de aula vá além de uma mera instrumentação de conteúdos e demonstração do processo de produção da notícia, sem uma discussão mais aprofundada das linhas editoriais dos veículos, dos processos ideológi- 
cos e manipulatórios que, cotidianamente, fazem parte das escolhas editoriais e das construçóes narrativas dos textos jornalísticos?

Certamente, não se trata, apenas, de ensinar os professores a "lerem" os jornais, mas sobretudo de possibilitar a eles, num primeiro momento, uma leitura do mundo para melhor compreenderem, eles próprios, o poder da mídia e o papel ocupado pelos diferentes veículos no espaço público. Só então poderão fazer a leitura crítica da mídia e, conseqüentemente, ensinar os alunos a pensarem, refletirem sobre os conteúdos noticiosos e, então, desenvolverem formas autônomas de pensar o mundo. Para isso, no entanto, é necessário, adquirir, também, o domínio da linguagem como ferramenta discursiva, e discernimento sobre a construção da narrativa jornalística e seus múltiplos sentidos atribuídos pelos seus diferentes agentes. Como alerta Zanchetta Jr.:

(...) para levar o aluno à reflexão histórica e superar o caráter introdutório e isolado predominante no trabalho com a imprensa e outros MC, talvez se devam enfatizar os conteúdos, mas principalmente as características dos gêneros e das práticas jornalísticas, além do funcionamento dos MC na sociedade contemporânea. Mais do que sensibilizar pela surpresa, pela urgência de solução para os problemas sociais e ambientais, pela abordagem do comportamento juvenil, estimular o aluno a perceber-se como agente midiático e não como receptor passivo de conteúdos ou cliente dos $\mathrm{MC}$ contribui para que ele possa se situar como indivíduo e como parte de uma coletividade. (2005, p. 1.508)

Para aprender a ler a mídia, decodificar os sentidos explícitos e implícitos na estrutura narrativa da imprensa, a subjetividade na construção da notícia, ao contrário da propalada objetividade, relato da realidade, jornalistas e professores que utilizam e discutem o papel da mídia na escola precisam, inicialmente, desenvolver alguns saberes que passam pela percepção crítica das estratégias e dos padróes na linguagem jornalística, tais como ocultamento, fragmentação e inversão, que possibilitam a manipulação deliberada da informação.

A mídia nunca é, portanto, apenas um "testemunho da realidade", como se ouve com freqüência. Expressões como a antiga "aconteceu, virou manchete" ou "o fato real em tempo real", entre tantas outras, estão longe da realidade da mídia. Trazer um fato à boca de cena, escolhendo-o para divulgar, implica deslocar um problema do âmbito 
Mídia, escola e leitura crítica do mundo

quase pessoal, dando-lhe características de problema da sociedade, o qual, a partir disso, ficará sob responsabilidade coletiva (Baccega, 2003, p. 24).

Ao capacitar professores para a utilização da mídia na escola, é necessário compreender as armadilhas da linguagem com suas múltiplas potencialidades e limites; identificar as marcas discursivas pelos diferentes modos de dizer para uma leitura dialógica do mundo; examinar a escolha intencional ou não dos verbos introdutórios de opinião, da utilização dos operadores argumentativos e do dito e do não-dito; saber reconhecer que dizer não é sinônimo de afirmar, enfatizar ou garantir; compreender quando se utiliza ainda, já, mas ou só; entender o porquê do processo de edição da notícia e como este se opera.

\section{Leitura obrigatória da mídia?}

Atualmente, como ocorre na maioria das cidades brasileiras, os projetos de mídia na escola são resultado de incursões das empresas de comunicação nas escolas, onde distribuem, gratuitamente, durante períodos de tempo distintos, exemplares de suas ediçóes para os professores usarem com suas turmas. Paralelamente, como se verifica com o projeto "Correio Escola", em Campinas, que iniciou suas atividades em 1992, sendo, portanto, pioneiro no estado de São Paulo, são oferecidos cursos de formação dos professores com o objetivo claro de mostrar a importância do veículo na sala de aula e de ensinar o processo de produção da notícia. É também de Campinas a Lei Municipal n. 9.355, de 1997, que introduz a leitura de jornais e revistas como atividade curricular no Ensino Fundamental, como lembra reportagem de Nice Bulhôes, de 1/8/2005, p. 7, do jornal Correio Popular da cidade.

Projeto semelhante, elaborado pelo deputado federal Carlos Neder (PL-RJ), tramita na Comissão de Educação e Cultura da Câmara Federal, obrigando à leitura diária de jornais e revistas na sala de aula,

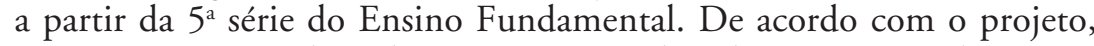
que vem provocando polêmica entre os educadores, o custo da aquisição dos exemplares seria do governo federal, numa exigência de três alunos por exemplar.

Parece até que os políticos brasileiros descobriram agora a importância da indústria cultural na formação da opinião pública e o papel 
da mídia na cultura escolar. Mas é uma discussão antiga e sua prática é antiga como a proposta pedagógica de Célestien Freinet na década de 1920, na França, por uma Escola Viva. Desde então, como lembra Elias (1997, p. 88), "a linguagem e a escrita são vistas como meios expressivos não exclusivos do professor ou de um manual. A criança pode falar livremente, escrever o que deseja. A imprensa prolonga a expressão escrita, permitindo-lhe ver o que escreve para ser lido pelos colegas e outros". Só que é sempre bom lembrar que na proposta de Freinet a criança constrói sua própria imprensa, fazendo assim sua leitura do ambiente em que vive, numa relação dinâmica e interativa da ferramenta para o aprendizado da leitura e da escrita.

Nos anos de 1960, o educador brasileiro Paulo Freire, assim como Freinet, acreditava na prática pedagógica comprometida como forma de reduzir a evasão escolar e formar educandos críticos. Uma das técnicas que defende é a elaboração do jornal escolar como um dos instrumentos que considera essenciais para motivar a escrita, "contribuindo para o desenvolvimento social e cultural do educando" (Elias, 1997, p. 101).

A grande diferença, dos projetos de mídia na escola conduzidos pelos grupos de comunicação e aqueles elaborados pelos próprios comunicadores ou educadores, é a forma como são elaborados e utilizados na sala de aula. Um exemplo é o projeto de "Educomunicação" coordenado pelo prof. Ismar Soares, da USP, incorporado por escolas da Rede Municipal de Ensino de São Paulo. Além de ensinar a leitura crítica da mídia convencional, promove o aprendizado e o manuseio das ferramentas dos suportes midiáticos no processo de construção de notícias. São os próprios jovens que produzem a radioescola. Em lugar de meros espectadores ou leitores, descobrem-se como sujeitos ativos no processo de construção da notícia, contribuindo assim para sua expressão social e, conseqüentemente, na melhoria da leitura do mundo e na articulação dos conteúdos programáticos da escola.

\section{Livros didáticos e imprensa}

Em que medida os livros didáticos do Ensino Fudamental, com as inserções cada vez mais freqüentes de textos jornalísticos, retirados de sua realidade contemporânea, podem, de fato, ser considerados ferramentas de conhecimento? Como podem os professores utilizar essas 
Mídia, escola e leitura crítica do mundo

migalhas de informação no processo de motivação e aprendizagem dos alunos? Questôes como estas são objeto de reflexão de diferentes autores, entre eles Zanchetta Jr.:

No livro didático, os textos surgem pasteurizados, ajustados à "cultura do fragmento", que, mesmo sendo uma das únicas alternativas para acesso a determinados conteúdos, incentiva o desprezo pela origem, pela história, pela integridade da informação (algo que se verifica em boa parte das coleções, no tocante aos textos da imprensa). Se a colagem de conteúdos sociais extraídos dos suportes midiáticos pode, de um lado, sensibilizar e ajudar no processo de conscientização dos alunos, também pode contribuir para o esvaziamento político da escola: o texto informativo emoldurado no LD, tomado como ponte para a participação nos problemas da sociedade, reforma a idéia de um papel que está além das possibilidades da escola. (2005, p. 1.507)

Desconhecer os problemas apontados por Zanchetta Jr. é negar a própria natureza da imprensa moderna, construída a partir da história do cotidiano e narrada em forma de mosaicos que dificultam a compreensão dos fatos e sua interpretação, uma vez que ela própria, a imprensa, é constituída de migalhas informativas, desprezando, na maior parte das vezes, a tessitura da história.

Reconhecer esta realidade não significa, porém, abrir mão de utilizar a mídia como fonte motivadora porque conectada com a realidade vivida por alunos e professores. Trata-se, na verdade, de fornecer os elementos necessários a alunos e professores para fazerem a leitura crítica da mídia a partir da leitura do mundo, tarefa ímpar da escola, que tem ou deveria ter os instrumentos necessários para estabelecer a necessária relação e conexão entre os fragmentos dos fatos e sua historicidade.

A mídia representa um campo autônomo do conhecimento que deve ser estudado e ensinado às crianças da mesma forma que estudamos e ensinamos a literatura, por exemplo. A integração da mídia à escola tem necessariamente de ser realizada nestes dois níveis: enquanto objeto de estudo, fornecendo às crianças e aos adolescentes os meios de dominar esta nova linguagem; e enquanto instrumento pedagógico, fornecendo aos professores suportes altamente eficazes para a melhoria da qualidade do ensino, porque adaptados ao universo infantil. (Belloni, 1991, p. 41)

Sabe-se, que a aquisição do conhecimento e a formação crítica de leitores não se dá pela leitura única de um veículo, mas justamente 
pela comparação entre eles. É exatamente pelo acesso ao contraditório, à percepção e ao reconhecimento de diferentes visões e interpretaçôes de um mesmo fato, pela polifonia das vozes, que é possível efetuar uma leitura do mundo que vá além da leitura das palavras.

O que mais preocupa, portanto, não são as narrativas jornalísticas destituídas de contexto nos livros didáticos, considerando que podem e devem servir apenas como pontos de partida para reflexão sobre determinados contextos. O grande desafio reside, no entanto, na discussão pedagógica sobre a utilização dessas estruturas narrativas como modelos de texto a serem seguidos, em alternância aos textos literários, na maior parte desconectados da realidade, mas ricos em estilo e criatividade, que povoavam com mais freqüência, no passado, os livros didáticos.

Neste sentido, os textos jornalísticos, sejam eles considerados informativos ou opinativos, devem ser compreendidos como escolhas de seus autores e impregnados pelo viés editorial de seus veículos. É claro que o gênero narrativo da imprensa deve fazer parte do processo de aquisição de conhecimento na escola. Entretanto, para ser usado na sala de aula, deve ser percebido, também, a partir de seus limites e não apenas de sua potencialidade.

Não são poucas as falhas presentes nas estruturas narrativas da imprensa. Além dos problemas de conteúdo, da falta de contextualização da informação, pecam, em grande parte, pela pobreza vocabular, pela imprecisão lingüística, pela falta de lógica e de clareza na exposição das idéias. Como a velocidade é parte integrante do processo de captação da informação e de sua produção, principalmente nos jornais diários, sejam eles impressos ou on-line, as estruturas narrativas da imprensa carregam consigo todos os problemas decorrentes da impossibilidade prática de revisão estilística e de conteúdo.

E é por este e não por outro motivo que os textos jornalísticos não podem ou não poderiam ser usados, como lembra Zanchetta Jr., como "parte do exercício gramatical" na escola, sob o risco de comprometermos ainda mais a aquisição da língua portuguesa. Podem ser usados como método científico de aprendizagem, em que o erro faça parte do processo de construção do conhecimento. Se utilizado como ponto de partida até mesmo para a identificação dos problemas lingüísticos, como fonte preliminar de pesquisas sobre temas da atualidade, pode se constituir num excelente instrumento de educação política e cidadã. 
Mídia, escola e leitura crítica do mundo

Para o atendimento pleno ao artigo 32, inciso I, da Seção III do Ensino Fundamental, da Lei de Diretrizes e Bases da Educação Nacional (LDB), que tem como um de seus objetivos "o desenvolvimento da capacidade de aprender, tendo como meios básicos o pleno domínio da leitura, da escrita e do cálculo", a escola não pode prescindir de outras ferramentas como o texto literário em suas múltiplas possibilidades (livro, crônicas, poesias etc.).

Em contrapartida, a indústria cultural, com sua diversidade de produtos, suportes e formatos (cinema, teatro, música e mídia em geral), por fazer parte da construção do imaginário de alunos, professores, pais e sociedade, por fazer parte do universo cotidiano das pessoas, precisa ser incorporada ao processo de aprendizagem numa relação crítica, em que o aprender a pensar (Pedro Demo) seja parte integrante do aprender a aprender (Paulo Freire) para o aprender a fazer (Célestien Freinet).

A apreensão da informação para sua transformação em conhecimento crítico e transformador passa, necessariamente, pela leitura do mundo, sem o que a leitura da palavra não levará a nada. "Sei tudo e não compreendo nada." Esta frase sintetiza a sociedade moderna, em que o simples acesso à informação em seus múltiplos formatos e vozes não é suficiente para a interpretação do mundo.

Para interpretar o mundo a escola é um agente social fundamental, mas não único. Não podemos, portanto, abrir mão de discutir, na sala de aula, o fenômeno da mídia, especialmente a televisão, mas partir dela para a compreensão crítica do mundo. E estamos o tempo todo a nos perguntar qual é, hoje, o papel da escola, dos pais? Que influência exercem na formação das crianças, dos jovens, constantemente bombardeados pela indústria cultural.

As crianças e os adolescentes nas sociedades contemporâneas aprendem mais como a televisão do que com os pais e professores? Como caracterizar este mais? Mais informaçōes, mais conhecimentos pontuais? Modelos de comportamento, opiniōes políticas? Possibilidades de desenvolver sua sensibilidade? A televisão oferece tudo isso e muito mais. A televisão, ao pretender reproduzir o universo real em sua complexidade, constrói um simulacro do mundo em que o indivíduo acaba se encontrando, assumindo as imagens produzidas como se fosse sua vida real. E estas imagens penetram a realidade, transformado-a, dando-lhe forma. (Belloni, 2001, p. 57) 
Utilizar a mídia na escola é o primeiro passo para a leitura do mundo. Em contrapartida, é essencial que o exercício cotidiano no uso da mídia na sala de aula não se limite à leitura de jornais, revistas ou dos veículos eletrônicos. Para se ler o mundo a partir dos olhares dos outros, é fundamental que seus leitores aprendam antes a ler o mundo em que vivem, por meio da construção de suas próprias narrativas. Só assim será possível a construção do conhecimento, a transformação do educando em sujeito de sua própria história. A aquisição do pensamento crítico é resultado da inserção e percepção direta do aluno como agente mobilizador na sua realidade.

Recebido em novembro de 2005 e aprovado em dezembro de 2005.

\section{Referências bibliográficas}

BACCEGA, M.A. Televisão e escola: uma mediação possível? São Paulo: SENAC, 2003.

BELLONI, M.L. O que é midia-educação. Campinas: Autores Associados, 2001.

BELLONI, M.L. Educação para a mídia: missão urgente da escola. Comunicação \& Sociedade, São Bernardo do Campo, v. 10, n. 17, p. 36-46, ago. 1991.

BERTOLETTI, E.C. A memória da comunicação impressa brasileira e o exercício da cidadania. In: Oliveira, M.J.C. (Org.). Comunicação pública. Campinas: Alínea, 2004. p. 81-96.

CALDAS, G. Leitura crítica da mídia. Comunicarte, Campinas, v. 19, n. 25, p. 133-144, 2002.

CALDAS, G. Ética e cidadania na formação do jornalista. Comunicação \& Sociedade, São Bernardo do Campo, v. 27, n. 44, p. 85-101, 2005.

CALDAS, G. Mídia e memória: a construção coletiva da história e o papel do jornalista como historiador do cotidiano. In: Bezzon, L.C. (Org.). Comunicaçāo, política e sociedade. Campinas: Alínea, 2005. p. 137-150. 
Mídia, escola e leitura crítica do mundo

CORTELLA, M.S. A escola e o conhecimento: fundamentos epistemológicos e políticos. São Paulo: Cortez, 2001.

DEMO, P. Educação e conhecimento: relaçōes necessárias, insuficientes e controversas. Petrópolis: Vozes, 2000.

ELIAS, M.D.C. Célestien Freinet: uma pedagogia de atividade e cooperação. Petrópolis: Vozes, 1997.

SANTAELLA, L. Produção de linguagem e ideologia. São Paulo: Cortez, 1996.

ZANCHETTA JUNIOR, J. Desafios para a abordagem da imprensa na escola. Educação \& Sociedade, Campinas, v. 26, n. 93, p. 14971510, set./dez. 2005. 